VISHNIAC, H. S. (1955). J. gen. Microbiol. 12, 464-472

\title{
The Activity of Steroids as Growth Factors for a Labyrinthula sp.
}

\author{
BY HELEN S. VISHNIAC \\ Department of Microbiology, Yale University, New Haven 11, Connecticut, U.S.A.
}

SUMMARY: Further investigation of the specificity of the steroid growth factor requirement of Labyrinthula vitellina var. pacifica has provided a detailed description of the structural requirements for activity. Active compounds include sterols and products of their autoxidation; the activity of the sterols is not, however, due to autoxidation during the assay period. The data obtained circumscribe the characteristics of the essential metabolite represented by this requirement but do not identify it.

Labyrinthula vitellina var. pacifica shows a steroid growth factor requirement which can be satisfied by cholesterol, $\Delta^{4}$-cholestenone, fucosterol, or $\beta$-sitosterol (Vishniac \& Watson, 1953) but not by any of twenty other steroids or by the non-steroids which annul fatty acid toxicity. Such a requirement represents inability to synthesize an essential metabolite. This paper describes the results of testing additional steroids as growth factors, in order to further circumscribe the possible characteristics of the metabolite.

\section{METHODS}

The following modifications of the assay method used by Vishniac \& Watson (1953) were found to improve the sensitivity and reliability of the assay for growth factor activity. (a) The basal medium of Vishniac (1955) is now used. (b) Steroid samples are added as freshly prepared ethanolic solutions, serially diluted so that 1 drop of solution/10 ml. medium is used. Addition is made after the medium has been distributed and sterilized. $(c)$ Inoculation is made directly from stock cultures, using one drop of a mature but recent culture into $10 \mathrm{ml}$. of medium. The few compounds which were tested by earlier methods are indicated by an asterisk * when results are given. After 7 days incubation at $20-21^{\circ}$, assays were read, in a Klett-Summerson photoelectric colorimeter with no. 42 filter.

Quantitative tests for cholesterol, $7 \alpha$ - and $\beta$-hydroxycholesterols, and cholestane-3 $\beta, 5 \alpha, 6 \beta$-triol were performed, using appropriate modifications of the method of Moore \& Baumann (1952) and Idler \& Baumann (1953). The last compound does not form a digitonide and in its free form is a weak chromogen, reaching maximum colour development at $620 \mathrm{~m} \mu$. in $7 \mathrm{~min}$. A much higher peak is present at $420 \mathrm{~m} \mu$. which continues to develop sufficiently slowly for use after $40 \mathrm{~min}$. The $7 \alpha$ - and $\beta$-hydroxycholesterols were also assayed by using the Lifschutz reagent according to Bergstrom \& Wintersteiner (1942a); 7-ketocholesterol was determined by optical density at $240 \mathrm{~m} \mu$. in absolute ethanol (Wintersteiner \& Bergstrom, 1941). 
The steroid preparations used were: cholesterol (Pfanstiehl Chemical Co.); cholestenone (Matheson, Coleman and Bell Inc.); cholestane, clionasteryl acetate, poriferasterol, neospongosteryl acetate, palysterol, haliclonasterol, $\alpha$-stellastenol, $\beta$-stellastenol, spinasterol, campesterol (gifts of Dr W. Bergmann, Department of Chemistry, Yale University); $\beta$-sitosterol (L. Light and Co. Ltd.); stigmasterol (gift of Dr W. van Wagtendonk, Department of Zoology, Indiana University); ergostane, ergostanol, $\Delta^{14(15)}$-ergostenol, $\Delta^{\mathbf{7}}$ ergostenol (gifts of Dr Seymour Bernstein, Lederle Laboratories); $\Delta^{8(14)}$-ergostenol, $\alpha$-dihydroergosterol, 7-ketocholesterol, 4( $(\beta)$-hydroxycholesterol (gifts of Dr Harris Rosenkrantz, The Worcester Foundation for Experimental Biology); squalene, pregnenolone, dehydroisoandrosterone (gifts of $\mathrm{Dr}$ K. Savard, The Worcester Foundation for Experimental Biology); $\Delta^{8(14)}$-cholestenyl benzoate, 7-ketocholesteryl acetate, $\Delta^{4}$-cholestenol, $3(\beta), 7(\beta)$-dihydroxycholestanyl acetate, $7(\alpha)$-hydroxycholesteryl-3-benzoate (gifts of Dr D. R. Idler, Fisheries Research Board of Canada); 7-dehydrocholesteryl acetate (gift of Dr R. G. Langdon, Department of Biochemistry, University of Chicago); cerebrosterol, cerebrostenolone, 24-ketocholesterol (gifts of Dr A. Ercoli, Vismara Terapeutici); $\Delta^{\mathbf{4}, 6}$-cholestadiene-3-one (gift of Dr J. Berlin, Syntex, S.A.); Windaus keto acid (gift of Dr T. Stadtman, National Heart Institute); lathosterol, 'lipid diol', Butenandt acid, Butenandt ketone, Diels acid, cholestane-3, 6 -dione, cholestane-5 $\alpha$-ol-3, 6-dione, cholestane-3 $\beta, 5 \alpha, 6 \beta$-triol, $\Delta^{5}$-cholestene-3-one, $\Delta^{4}$-cholestene-6 $\beta$-ol-3-one, $\Delta^{4}$-cholestene-3, 6-dione (gifts of Dr L. F. Fieser, Department of Chemistry, Harvard University); $\beta$-hydroxy$\beta$-methyl glutaric acid, $\beta$-methyl glutanoic acid (gifts of Dr F. Dituri, Department of Physiological Chemistry, University of Pennsylvania); $7(\alpha)$-hydroxycholesterol and $\Delta^{6}$-cholestenyl acetate (gifts of Dr 0 . Wintersteiner, The Squibb Institute for Medical Research). Compounds received as esters were saponified before use. $\Delta^{\mathbf{3} 5}$-cholestadiene-7-one was made from 7 -ketocholesteryl acetate (Bergstrom \& Wintersteiner, 1941).

Many of these preparations were available in such minute quantities that they could only be assayed as received. When sample size permitted, preparations were recrystallized several times from methanol and acetone. Recrystallization was particularly helpful in removing the toxic contaminants usually found in aged or off-colour preparations. When possible, the melting points of preparations were taken in a Dow-Corning No. 200 Fluid bath. Melting points given are uncorrected. Assays were run with 1, 2, 5, 10, 20 and $50 \mu \mathrm{g}$. steroid/10 ml. of medium. A duplicate series with $50 \mu \mathrm{g}$. cholesterol/ $10 \mathrm{ml}$. of medium, added before sterilization, was used as toxicity control.

\section{RESULTS}

The difficulties encountered because of small sample sizes and the sensitivity of Labyrinthula vitellina var. pacifica to toxic contaminants in many of the samples made it possible to obtain trustworthy response curves covering the complete concentration range with only a few steroids. The activity of representative steroids for which good samples were available is shown in Fig. 1. 
Of those related steroids which differed only in the tail portion of the cholesterol molecule in:

(a) Length. Pregnenolone (m.p. 187-190 ${ }^{\circ}$ ) was, as progesterone, completely inhibitory; dehydroisoandrosterone (m.p. $150^{\circ}$ ) inactive.

(b) Substituents at C24. Campesterol* (C24a methyl), clionasterol (C24a ethyl), $\beta$-sitosterol (C24b ethyl) (m.p. 137 ${ }^{\circ}$ ), $\alpha$-stellastenol (C 24a methyl), and $\Delta^{8(14)}$-ergostenol (C24b methyl) (m.p. $\left.131^{\circ}\right)$ were active. The recrystallized preparation of $\beta$-sitosterol used was as active in the lower range of concentra-

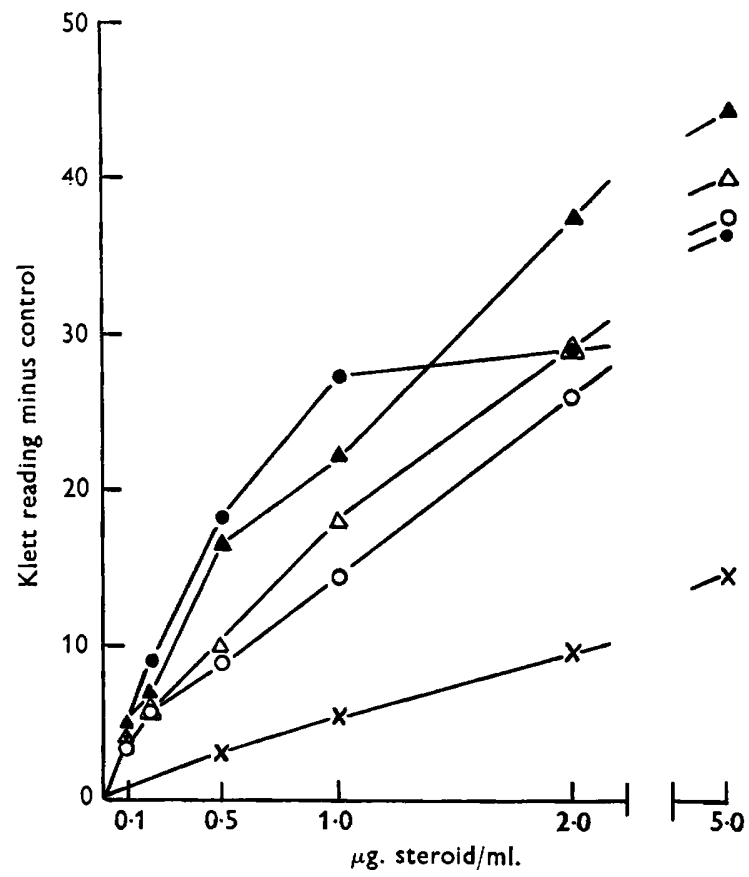

Fig. 1. Growth response of Labyrinthula vitellina var. pacifica to varying concentrations of steroids. Controls showed no growth. $X=$ stigmasterol; $O=$ cholesterol; $\triangle=\triangle^{8,}{ }^{14}$-ergostenol; $\Delta=$ cholestane-3 $\beta, 5 \alpha, 6 \beta$-triol; $\bigcirc=$ cholestenone.

tions $\left(10 \mu \mathrm{g} . / \mathrm{ml}\right.$. and below) as the recrystallized cholesterol (m.p. $\left.148 \cdot 5-149^{\circ}\right)$ for which data are given in Fig. 1, but failed to keep pace at higher concentrations. The other $\Delta^{5}$-stenols used were considerably less active than cholesterol at all concentrations, presumably because they were obviously inferior preparations, although growth in the presence of added cholesterol was not significantly affected. The same was true of palysterol* and haliclonasterol*, of incompletely known structure. Recrystallized cerebrosterol ( $\Delta^{5}$-cholestene-3 $\beta, 24 \xi^{\prime}$-diol; m.p. 175-175.5 ${ }^{\circ}$ ) and 24-ketocholesterol (m.p. $135^{\circ}$ ) were inactive and were toxic at $5 \mu \mathrm{g}$. $/ 10 \mathrm{ml}$. or more. Recrystallized cerebrostenolone ( $\Delta^{4}$-cholestene-3, 24-dione; m.p. $\left.135^{\circ}\right)$ was inactive and toxic at $20 \mu \mathrm{g} . / 10 \mathrm{ml}$.

(c) Unsaturation at $C 22(23)$. Recrystallized poriferasterol (m.p. $\mathbf{1 3 2}^{\circ}$ ) and stigmasterol (m.p. $137^{\circ}$ ) showed, as did brassicasterol previously, some activity. 
Since the stigmasterol preparation appeared good and had full activity for a Paramecium sp. (as tested by Dr W. J. van Wagtendonk), this activity is now considered to be real (see Fig. 1).

Of those related steroids which differed in the hydrogenation of the ring portion of the cholesterol molecule which were:

(a) Saturated. Cholestane*, ergostane*, and ergostanol*, as cholestanol and coprosterol previously, were inactive. Neospongosterol showed traces of activity (20 $\mu \mathrm{g}$. giving the growth produced by $1 \mu \mathrm{g}$. of the most active compound) presumed to be due to sterol impurities.

(b) Singly unsaturated. $\Delta^{4}$-Cholestenol (allocholesterol; m.p. 129.5 ${ }^{\circ}$ ) was only slightly more active than stigmasterol. This activity could be the result of non-biological cholesterol formation during the assay period. Recrystallized $\Delta^{4}$-cholestenone was one of the most active steroids (see Fig. 1 ); $\Delta^{5}$-cholestene3-one had only about the activity of cholesterol; $\Delta^{6}$-cholestenol (m.p. 134.5$136^{\circ}$ ) was presumed inactive since growth occurred only with $50 \mu \mathrm{g} . / 10 \mathrm{ml}$. and even then merely equalled the growth produced by $2 \mu \mathrm{g}$. of the most active steroids. $\Delta^{7}$-Ergostenol, 5-dihydroergosterol, and spinasterol were inactive; the slight activity of lathosterol $\left(\Delta^{7}\right.$-cholestenol) was halved on recrystallization (so that maximum growth, at $10 \mu \mathrm{g}$. was equal to the growth produced by $1 \mu \mathrm{g}$. of the most active compound). I conclude that $\Delta^{7}$-stenols are not active. Recrystallized $\Delta^{8(14)}$-ergostenol (m.p. $131^{\circ}$ ) was slightly more active than cholesterol (see Fig. 1); $\Delta^{8(14)}$-cholestenol (m.p. 120-121 ${ }^{\circ}$, and recrystallized $\alpha$-stellastenol were equally active at $5 \mu \mathrm{g} . / 10 \mathrm{ml}$. or below. $\Delta^{14(15)}$. ergostenol* and $\beta$-stellastenol* were inactive.

(c) Dienes. 7 -Dehydrocholesterol (sintered at $128^{\circ}$ ) was about as active as cholesterol. The absence of a good melting point makes the significance of this result rather doubtful, although ergosterol has previously shown some very slight, variable, activity. Both preparations had to be recrystallized to free them of toxic material. Both compounds are known to deteriorate during recrystallization (Huber, Ewing \& Kriger, 1945).

The results of testing the products of autoxidation of cholesterol suggested that the naturally occurring sterols might be active by virtue of autoxidation occurring during the 7-day incubation period of the assays. Cholesterol undergoes rapid autoxidation in colloidal aqueous solution (Bergstrom \& Wintersteiner, 1942b) yielding $7 \alpha$-hydroxycholesterol, 7 -keto-cholesterol, $\Delta^{3,5}$-cholestadiene-7-one (Wintersteiner \& Bergstrom, 1941; Bergstrom \& Wintersteiner, 1941) and cholestane-3 $\beta, 5 \alpha, 6 \beta$-triol (Mosbach, Nierenberg \& Kendall, 1953). At lower temperatures $\left(37^{\circ}\right) 7$-ketocholesterol predominates (Bergstrom \& Wintersteiner, 1942a). Recrystallized 7-ketocholesterol (m.p. $172-172 \cdot 5^{\circ}$ ) gave an activity curve almost superimposable upon that of $\Delta^{\text {(14) }}$-ergostenol (see Fig. 1). Cholestane-3 $\beta, 5 \alpha, 6 \beta$-triol (m.p. 237-238 ${ }^{\circ}$ ) was even more active (see Fig. 1). $7 \alpha$-Hydroxycholesterol (m.p. 150-151 ${ }^{\circ}$ ) was as active (at low concentrations only) as cholestenone.

Since autoxidation is catalysed and inhibited by various metallic ions (Bergstrom \& Wintersteiner, 1942b), it was impossible to predict whether it would occur in the complex medium used. Lots $(250 \mathrm{ml}$.) of medium prepared 
as for assay experiments were, therefore, distributed in Fernbach flasks to form layers 7-8 $\mathrm{mm}$. deep. The flasks were then plugged, autoclaved, and cooled to $20^{\circ}$. In separate experiments 1.25 and $7.5 \mathrm{ml}$. portions of an $0.2 \%$ $(\mathrm{w} / \mathrm{v})$ solution of freshly recrystallized cholesterol in $95 \%(\mathrm{w} / \mathrm{v})$ ethanol in water were added to each lot of medium. After 7 days incubation at 20-21 ${ }^{\circ}$ the flask contents were extracted continuously with ether under a stream of alkaline-pyrogallol-washed nitrogen for $8 \mathrm{hr}$., or, when these precautions proved unnecessary, shaken with four 70 to $30 \mathrm{ml}$. portions of ether. In the latter case, backwashing each portion of ether with $10 \mathrm{ml}$. distilled water was necessary to break the emulsion stabilized by the agar of the medium. The ether extract was then evaporated under vacuum and dried in a vacuum desiccator over silica gel. Although difficulty was experienced in recovering cholesterol from the less concentrated preparation by the methods outlined, no 7 min. excess was found in the Moore-Baumann test, no Lifschutz reaction was given by a sample equal to $2 / 10$ of the residue of two flasks, and no peak appeared at $240 \mathrm{~m} \mu$. From the more concentrated preparation $99 \%$ of the cholesterol was recovered. There were again no indications of the presence of any fast Moore-Baumann steroids, Lifschutz-reacting steroids, or substances giving peaks in the ultraviolet. Autoxidation does not occur under the conditions of these experiments.

The results of testing other products of the mild oxidation of cholesterol were as follows:

(a) Cholestanes. Cholestane-3, 6-dione (m.p. 170-171 ${ }^{\circ}$ gave an activity curve almost superimposable upon that of cholestane-triol (see Fig. 1). Recrystallized cholestane-3 $\beta, 7 \beta$-diol (m.p. $150-153^{\circ}$ ) was inactive and showed increasing toxicity with increasing concentration. Cholestane-5 $\alpha$-ol-3, 6-dione (m.p. 244-245 ${ }^{\circ}$, used as an acetone solution, was inactive. Acetone was not responsible for absence of activity.

(b) Cholestenes. The activity of $\Delta^{4}$ and $\Delta^{5}$-cholestenone has been mentioned earlier. $\Delta^{4}$-Cholestene-6 $\beta$-ol-3-one (m.p. $187-188^{\circ}$ ) was about equally active as cholestane-triol; $\Delta^{4}$-cholestene-3, 6-dione (m.p. 123-124 ${ }^{\circ}$ ) as cholesterol. Recrystallized $4 \beta$-hydroxycholesterol (m.p. $177^{\circ}$ ) was inactive and slightly inhibitory at the higher concentrations used.

(c) Cholestadienes. $\Delta^{3,5}$-Cholestadiene-7-one (m.p. $112^{\circ}$ ) was inactive. $\Delta^{4,6_{-}}$ cholestadiene-3-one (m.p. $\left.75-76^{\circ}\right)$ was as active as $\left.\Delta^{8(14)}\right)$-ergostenol at $5 \mu \mathrm{g} . / 10 \mathrm{ml}$. and below, but increasing concentrations had no greater effect on growth.

Products of oxidation so violent as to open or shorten a ring were inactive and more or less toxic: Windaus keto acid* was completely inhibitory; Diels acid and Butenandt ketone inhibitory at $10 \mu \mathrm{g}$. or more $/ 10 \mathrm{ml}$; Butenandt acid at $20 \mu \mathrm{g}$. or more $/ 10 \mathrm{ml}$.

Cholesterol from natural sources contains steroid contaminants in amounts too small to account for its activity. The possibility that activity was due to a non-steroid contaminant, while rather far-fetched in view of the indirectly biological provenance of many active compounds, led us to examine the 'lipid diol' $\left(\mathrm{CH}_{3} \cdot \mathrm{CH}_{2} \cdot \mathrm{CH}\left(\mathrm{CH}_{3}\right) \cdot \mathrm{CH}_{2} \cdot\left(\mathrm{CH}_{2}\right)_{15} \cdot \mathrm{CHOH} \cdot \mathrm{CH}_{2} \mathrm{OH}\right)$ isolated by Dr L. F. Fieser from cholesterol; it was inactive. 
The possibility that the effective block in biosynthesis of the steroid metabolite required by these labyrinthula isolates might lie in an early portion of the pathway led us to examine non-steroid precursors of cholesterol. Squalene* a precursor of cholesterol (Langdon \& Bloch, 1952, 1953a), was inactive and became toxic at $25 \mu \mathrm{g}$. $/ 10 \mathrm{ml}$. $\beta$-Hydroxy- $\beta$-methylglutaric acid (Rabinowitz \& Gurin, 1954a) and $\beta$-methylglutaconic acid (Rabinowitz \& Gurin, 1954b) have also been suggested as precursors of cholesterol; neither was active.

\section{DISCUSSION}

The data of Vishniac \& Watson (1953) indicated that the steroid growth factor requirement of Labyrinthula vitellina var. pacifica could be satisfied by cholesterol or derivatives formed by the addition of a C24b ethyl group or C24 vinyl group or by mild oxidation to $\Delta^{4}$-cholestenone. Activity was abolished by changing the orientation of, or esterifying, the C3 hydroxyl, by saturating the double bond, or by introducing C22(23) unsaturation (or making more radical alterations) in the tail of the cholesterol molecule. The experiments reported above make it possible to specify further that:

(1) Only steroids with a $3 \beta-\mathrm{OH}$ or 3 -keto group are active.

(2) Only $\mathrm{C} 27,28$ and 29 steroids are active.

(3) Of these, both of the possible C24 methyl and ethyl epimers derived from active cholestenols are active. Cholesterol derivatives oxidized at C24 are inactive.

(4) If no other oxygen function (than as (1)) is present, only steroids unsaturated at $\mathrm{C} 4(5)$, or $\mathrm{C5}(6)$, or $\mathrm{C8}(14)$ are active. Ring-saturated steroids, or those unsaturated only at $\mathrm{C} 6(7), \mathrm{Cr}(8)$, or $\mathrm{C14}(15)$, are inactive.

(5) $\Delta^{5,7}(?)$ and $\Delta^{4,6}$-Dienes are active. $\Delta^{5,22}$-Dienes have low activity.

(6) Steroids with more than one oxygen function on the rings need not be unsaturated: cholestane-3 $\beta, 5 \alpha, 6 \beta$-triol and cholestane-3,6-dione are active. However, cholestane-3 $\beta, 7 \beta$-diol and cholestane- $5 \alpha$-ol-3, 6-dione are inactive.

(7) The activity of cholesterol is retained when 7 -keto or $7 \alpha-\mathrm{OH}$ functions are added, but not when a $4 \beta-\mathrm{OH}$ is added. $\Delta^{4}$-Cholestenone activity is likewise retained when 6 -keto or $6 \beta-\mathrm{OH}$ groups are added.

It seems highly unlikely that the apparent activity of these steroids (excepting allocholesterol and 7-dehydrocholesterol) is due to chemical contamination or to non-biological changes occurring during the assay period. Any active compound must then belong to a biochemical family consisting of (a) an essential metabolite, $(b)$ natural precursors in its biosynthesis, and (c) compounds biologically convertible into the metabolite, but not normal precursors in biosynthesis. This family probably arises after the cyclization of squalene and certainly does not include any of the short-tailed descendants of cholesterol (Zabin \& Barker, 1953; Siperstein, Harold, Chaikoff \& Dauben, 1954). Singly unsaturated steroids are active only when they derive their unsaturation from squalene, folded as postulated by Bloch (Langdon \& Bloch, $1953 b)$.

Since the relative activities of useful steroids constitute insufficient evidence 
for assigning any one of them the role of essential metabolite, other lines of inquiry must be adopted. Isolation of steroids from related Labyrinthula spp. which do not require a steroid as nutrient is being attempted.

Comparison of the specificity patterns of other organisms with similar requirements yields a picture capable of several interpretations; such a comparison is made in Table 1. One other micro-organism, Saccharomyces cerevisiae $\mathbf{S C}-\mathbf{1}$ (DCL), has been reported to require a steroid growth factor on a defined medium when grown anaerobically (Andreasen \& Stier, 1953); no study of specificity was made and cholesterol, ergosterol, or anti-stiffness factor (stigmasterol) satisfied the requirement.

Table 1. The specificity of the steroid growth factor requirements of micro-organisms

\begin{tabular}{|c|c|c|c|c|}
\hline & $\begin{array}{c}\text { Trichomonas } \\
\text { columbae } \\
\text { (Cailleau, } \\
\text { 1937) }\end{array}$ & $\begin{array}{c}\text { Paramecium } \\
\text { aurelia } \\
\text { (Conner \& van } \\
\text { Wagtendonk, } \\
\text { 1955) }\end{array}$ & $\begin{array}{l}\text { Labyrinthula } \\
\text { (present work) }\end{array}$ & $\begin{array}{c}\text { PPLO* } \\
\text { (Edward \& } \\
\text { Fitzgerald, } \\
\text { 1951) }\end{array}$ \\
\hline \multicolumn{5}{|l|}{ 3 $\beta$-OH-Steranes : } \\
\hline Cholestanol & + & $\mathbf{0}$ & $\mathbf{0}$ & + \\
\hline Coprosterol & o & $\mathbf{0}$ & $\mathbf{0}$ & o \\
\hline Ergostanol & + & $\mathbf{0}$ & $\mathbf{0}$ & . \\
\hline \multicolumn{5}{|l|}{$\Delta^{5}$-Ene-3-ols : } \\
\hline Cholesterol & + & $\mathbf{0}$ & + & + \\
\hline$\beta$-Sitosterol & $0(?)$ & + & + & . \\
\hline Clionasterol & + & + & + & . \\
\hline Fucosterol & . & + & + & . \\
\hline$\Delta^{5,22 \text {-Diene-3-ols : }}$ & & & & \\
\hline $\begin{array}{c}\text { Stigmasterol } \\
\Delta^{8(14)-E n e-3-o l s:}\end{array}$ & $\mathbf{0}$ & + & \pm & + \\
\hline $\begin{array}{c}\alpha \text {-Ergostenol } \\
\Delta^{6,7} \text {-Diene-3-ols: }\end{array}$ & + & 0 & + & . \\
\hline 7-Dehydrocholesterol & + & . & $+(?)$ & . \\
\hline $\begin{array}{l}\text { 22-Dihydrogosterol } \\
\Delta^{\mathbf{5}, 7,22} \text {-Triene-3-ols: }\end{array}$ & + & . & & . \\
\hline $\begin{array}{l}\text { Ergosterol } \\
\Delta^{5} \text {-Ene-diols : }\end{array}$ & \pm & $\mathbf{0}$ & $0(?)$ & $\mathbf{0}$ \\
\hline $\begin{array}{l}\Delta^{5} \text {-Cholestene-3, 4-diol } \\
\text { Oxidation products: }\end{array}$ & + & . & $\mathbf{0}$ & . \\
\hline$\Delta^{5}$-Cholestenone & $\mathbf{0}$ & . & + & . \\
\hline$\Delta^{4,22}$-Stigmastadienone & & $\dot{t}$ & . & : \\
\hline Cholestane-3, 6-dione & $\mathbf{0}$ & . & + & . \\
\hline
\end{tabular}

It is evident from Table $\mathbf{1}$ that while no single steroid is active for all of these micro-organisms, further investigation might easily indicate a common factor. The differences in pattern are, however, sufficiently great to make tenable the hypothesis that no single essential metabolite is represented by these requirements. The most conspicuous differences are the use of saturated $3 \beta$-hydroxy sterols by Trichomonas spp. and pleuropneumonia-like organisms and the use of certain oxidation products of active sterols by Paramecium aurelia and Labyrinthula vitellina var. pacifica. These differences, and the multiplicity of roles assumed by steroids in mammals suggest that different 
metabolites with different roles may be represented. Another possibility, that a single biochemical role might be assumed by different sterols in different organisms is suggested by the use of $\mathrm{C} 27$ steroids by the Labyrinthula sp., while Paramecium aurelia uses only $\mathrm{C} 28$ or $\mathrm{C} 29$ steroids. The sterols of various taxonomic groups are usually characteristic and significant in biochemical evolution (Bergmann, 1949, 1953; Heilbron, 1942). A non-characteristic sterol might still be active, either directly by virtue of chemical homology or indirectly by conversion, in the same reactions as was the steroid which occurred naturally in a particular group. Studies on the metabolism of labelled cholestanol, cholesterol, and cholestenone by the appropriate micro-organisms should at least clarify these questions.

We wish to thank those (mentioned in the text) who contributed the samples of steroids which made this study possible. We are grateful to Dr K. Savard and Prof. W. Bergmann for advice and stimulating discussions, and to $\mathrm{Mr}$ S. Mills for technical assistance. These studies were aided by a grant from the Eugene Higgins Fund and by a contract between the Office of Naval Research, Department of the Navy, and Yale University, NR 135-241.

\section{REFERENCES}

Andreasen, A. A. \& Stier, T. J. B. (1953). Anaerobic nutrition of Saccharomyces cerevisiae. I. Ergosterol requirement for growth in a defined medium. J. cell. comp. Physiol. 41, 23.

Bergmann, W. (1949). Comparative biochemical studies on the lipids of marine invertebrates, with special reference to the sterols. J. Mar. Res. 8, 137.

Bergmann, W. (1953). The plant sterols. Annu. Rev. Pl. Physiol. 4, 383.

Bergstrom, S. \& Wintersteiner, O. (1941). Autoxidation of sterols in colloidal aqueous solutions. I. The nature of the products formed from cholesterol. J. biol. Chem. 141, 597.

Bergstrom, S. \& Wintersteiner, O. (1942a). Autoxidation of sterols in colloidal aqueous solutions. III. Quantitative studies on cholesterol. J. biol. Chem. 145, 309.

Bergstrom, S. \& Wintersteiner, O. (1942b). Autoxidation of sterols in colloidal aqueous solutions. IV. The influence of esterification and of constitutional factors. J. biol. Chem. 145, $32 \%$.

Cailleau, R. (1937). La nutrition des flagellés tétramitidés. Les sterols, facteurs de croissance pour les trichomonades. Ann. Inst. Pasteur, 59, 7.

ConNer, R. L. \& vaN WAGTENDONK, W. J. (1955). Steroid requirements of Paramecium aurelia. J. gen. Microbiol. 12, 31.

Edward, D. G. FF. \& Fitzgerald, W. A. (1951). Cholesterol in the growth of organisms of the pleuropneumonia group. J. gen. Microbiol. 5, 576.

Heilbron, I. M. (1942). Some aspects of algal chemistry. J. chem. Soc. p. 79.

Huber, W., Ewing, G. W. \& Kriger, J. (1945). The absorption spectra of the vitamins and pro-vitamins D. J. Amer. chem. Soc. 67, 609.

Idler, D. R. \& BaumanN, C. A. (1953). Skin sterols. III. Sterol structure and the Liebermann-Burchard reaction. J. biol. Chem. 203, 389.

LANGDON, R. G. \& Bloch, K. (1952). The biosynthesis of squalene and cholesterol. J. Amer. chem. Soc. 74, 1869.

Langdon, R. G. \& Bloch, K. (1953a). The biosynthesis of squalene. J. biol. Chem. $200,129$.

Langdon, R. G. \& Bloch, K. (1953b). The utilization of squalene in the biosynthesis of cholesterol. J. biol. Chem. 200, 135. 
Moore, P. R. \& Baumann, C. A. (1952). Skin sterols. I. Colorimetric determination of cholesterol and other sterols in skin. J. biol. Chem. 195, 615.

Mosbach, E. H., Nierenberg, M. \& Kendali, F. E. (1953). Separation of the airoxidation products of cholesterol by column partition chromatography. J. Amer. chem. Soc. 75, 2358.

Rabinowitz, J. L. \& GURIN, S. (1954a). Biosynthesis of cholesterol and $\beta$-hydroxy$\beta$-methyl glutaric acid by extracts of liver. J. biol. Chem. 208, 307.

Rabinowitz, J. L. \& GuRIN, S. (1954b). The biosynthesis of radioactive cholesterol, $\beta$-methylglutaconic acid and $\beta$-methylcrotonic acid by aqueous extracts of liver. J. Amer. chem. Soc. 76, 5168.

Siperstein, M. D., Harold, F. M., Chaikoff, I. L. \& Dauben, W. G. (1954). $\mathrm{C}^{14}$-cholesterol. VI. Biliary end-products of cholesterol metabolism. J. biol. Chem. 210, 181.

Vishniac, H. S. \& Watson, S. W. (1953). The steroid requirements of Labyrinthula vitellina var. pacifica. J. gen. Microbiol. 8, 248.

VISHNIAC, H. S. (1955). .The nutritional requirements of isolates of Labyrinthula spp. J. gen. Microbiol. 12, 455.

Wintersteiner, O. \& Bergstrom, S. (1941). The products formed by the action of oxygen on colloidal solutions of cholesterol. J. biol. Chem. 137, 785 .

ZABIN, I. \& BARKER, W. F. (1953). The conversion of cholesterol and acetate to cholic acid. J. biol. Chem. 205, 633.

(Received 20 December 1954) 